\title{
Kajian Integratif Urgensi Kemitraan Sekolah dalam Menjaga Keberlangsungan Hidup Lembaga Pendidikan Islam
}

\author{
Endah Winarti ${ }^{1}$, Zainal Abidin ${ }^{2}$, Akhmad Fauzi Hamzah ${ }^{3}$ \\ 1,2,3 IAI Darullughah Wadda'wah Pasuruan \\ 1endahwinarti002@gmail.com, ${ }^{2}$ zainal.almadaniyah@gmail.com, ${ }^{3}$ sajadah15@gmail.com
}

\begin{abstract}
Previous theoretical and empirical studies have directed partnerships as part of educational activities. However, implementation at the level of Islamic educational institutions is still less than optimum, and studies on the importance of partnerships in Islamic educational institutions are also minimal. In fact, during the current pandemic, partnerships are not the only choice activity for Islamic educational institutions to carry out but are a must for achieving educational goals. For this reason, there is a need to present an integrative literature review on partnerships in the context of Islamic educational institutions that analyzes the crucial reasons for implementing partnerships systematically by Islamic educational institutions. By first discussing what school partnerships are and who is involved in school partnerships, the results of the integrative literature review suggest three crucial reasons why Islamic Education Institutions need to develop partnerships: sustainability, good governance, and quality improvements. The development of school partnerships is urgent and strategic, not only for the sake of realizing the goals of Islamic education but also as an effort to maintain the viability of Islamic education institutions in rapid environmental changes.
\end{abstract}

Keywords: Good Governance School, Islamic School Partnership, Quality Improvement School, School Sustainability

\begin{abstract}
Abstrak
Kajian teoretis dan empiris terdahulu mengarahkan kemitraan sebagai bagian dari kegiatan pendidikan. Namun demikian, pelaksanaan di tingkat lembaga pendidikan Islam masih kurang optimal dan kajian-kajian tentang pentingnya kemitraan di lembaga pendidikan Islam juga didapati masih minim. Padahal, di tengah pandemi saat ini, kemitraan tidak hanya menjadi aktivitas pilihan untuk dilaksanakan oleh lembaga pendidikan Islam. Namun menjadi keharusan demi tercapainya tujuan pendidikan. Untuk itu, terdapat kebutuhan menghadirkan kajian literatur integratif tentang kemitraan pada konteks lembaga pendidikan Islam yang menganalisis alasan penting dilaksanakannya kemitraan secara sistematis oleh lembaga pendidikan Islam. Dengan terlebih dahulu mengemukakan pembahasan apakah kemitraan sekolah itu dan siapa sajakah yang terlibat dalam kemitraan sekolah. Hasil kajian literatur integratif mengemukakan tiga alasan penting mengapa lembaga pendidikan Islam perlu mengembangkan kemitraan: sustainability; good governance; dan quality improvement. Pengembangan kemitraan sekolah menjadi urgen dan strategis, tidak hanya demi
\end{abstract}


mewujudkan tujuan pendidikan Islam, namun sekaligus sebagai upaya menjaga kelangsungan hidup lembaga pendidikan Islam di tengah kedaruratan pandemi, persaingan, dan perubahan lingkungan yang sangat cepat.

Kata Kunci: Keberlangsungan Sekolah, Kemitraan Sekolah, Mutu Sekolah, Tata Kelola Sekolah

\section{Pendahuluan}

Penyebaran masif virus corona 2019 (Covid-19) telah melahirkan pandemi yang menimpa dunia sejak dua tahun terakhir berdampak pada lahirnya krisis pada semua lini kehidupan manusia, termasuk bidang pendidikan. Semua komponen pendidikan berinovasi dan berstrategi untuk terus berupaya mengatasi dan meminimalkan dampak negatif dan tetap berpegang pada upaya terwujudnya tujuan pendidikan. ${ }^{1}$ Pandemi mengajarkan pentingnya optimalisasi pengelolaan lingkungan lembaga pendidikan untuk dapat bersinergi dan bekerjasama mencapai tujuan bersama. Kedaruratan ini menjadi tantangan bagi para stakeholder pendidikan seperti: pengelola pendidikan, pendidik, peserta didik, orang tua, dan bahkan masyarakat. $^{2}$

Bahasan mengenai hubungan dan keterlibatan pengelola sekolah, pendidik, dan lingkungan pendidikan menjadi topik yang tidak hanya menarik, tetapi juga menjadi urgen untuk dibicarakan. Kemitraan sekolah memainkan peran penting dalam kesuksesan sebuah sekolah, ${ }^{3}$ terlebih pada kondisi pandemi saat ini. Kemitraan dalam bidang pendidikan mulai muncul dan dikenal di beberapa dekade terakhir ini. Meski demikian, kemitraan sekolah yang berkembang lebih bersifat episodik dan reaktif daripada bersifat ongoing dan proaktif. ${ }^{4}$ Bahkan di tahun 90-an hubungan antara keluarga dan sekolah sangat jarang dan bersifat searah. $^{5}$ Berbagai penelitian tidak hanya menggambarkan kemitraan sekolah pada sisi terbaiknya, melainkan juga sisi terburuknya. Salah satu sisi terburuknya menunjukkan bahwa pembagian peran dan tanggung jawab antara sekolah dan keluarga dipandang hanya sebagai retorika. ${ }^{6}$

\footnotetext{
${ }^{1}$ Sumitra Pokhrel dan Roshan Chhetri, "A Literature Review on Impact of Covid-19 Pandemic on Teaching and Learning," Higher Education for the Future 8, no. 1 (2021): 133-41.

${ }^{2}$ Princess Zarla J. Raguindin, Ruby Leah S. Lising, dan Zhanina U. Custodio, "Strategies for Parental Involvement during Emergency Remote Teaching Scale: Its Psychometric Properties.," European Journal of Educational Research 10, no. 1 (2021): 427-39.

${ }^{3}$ Judith Gross, "Strong School-Community Partnerships in Inclusive Schools Are" Part of the Fabric of the School. We Count on Them".," School Community Journal 25, no. 2 (2015): 9-34.

${ }^{4}$ Jodi S. Bullard, Barbara S. McAlister, dan Jenifer M. Chilton, "Covid-19: Planning and Postpandemic partnerships," NASN School Nurse 36, no. 2 (2021): 80-84.

5 I.-wah Pang, "School-family-community Partnership in Hong Kong-perspectives and Challenges," Educational Research for Policy and Practice 3, no. 2 (2004): 109-25.

${ }^{6}$ Sandra L. Christenson, "The family-school Partnership: An Opportunity to Promote the Learning Competence of All Students," School Psychology Review 33, no. 1 (2004): 83-104.
} 
Implementasi kemitraan sekolah pada konteks Lembaga Pendidikan Islam (LPI) juga bukannya tanpa kendala. Partisipasi dan interaksi masyarakat masih kurang dan kemitraan yang terjadi di lapangan masih belum maksimal untuk saling menguntungkan kedua belah pihak dalam posisi sederajat. ${ }^{7}$ Keterlibatan masyarakat terhadap kegiatan pendidikan di LPI bisa dikatakan nihil. ${ }^{8}$ Jika di masa lalu keluarga dan pendidik mungkin berharap bahwa sekolah dapat melaksanakan tugasnya sendiri, namun yang terjadi sekarang sekolah membutuhkan keluarga dan keluarga membutuhkan sekolah.

Keberadaan pandemi menekankan kebutuhan akan kemitraan yang semakin kuat antar pengelola pendidikan. ${ }^{9}$ Pelaksanaan pendidikan pada masa pandemi mengharuskan adanya pembagian peran dan tanggung jawab antara pendidik di sekolah dan orang tua di rumah. Pembelajaran jarak jauh secara online berdampak peningkatan tanggung jawab keluarga dan bersifat kompleks karena menuntut mereka untuk lebih terlibat secara aktif demi tercapainya tujuan pendidikan. ${ }^{10}$ Bahkan ketika orang tua turut terlibat dalam proses pendidikan anak, maka peserta didik cenderung lebih baik di sekolah. ${ }^{11}$ Kondisi ini menjadi penting untuk tetap menjaga kemitraan dengan elemen-elemen lembaga pendidikan agar semua agenda tetap terlaksana dengan berbagai alternatif. Bersikap adaptif akan membantu untuk mempersiapkan sistem pendidikan terhadap kondisi ketidakpastian yang mungkin bisa saja kembali terjadi di masa mendatang. ${ }^{12}$

Pendidikan bukanlah hasil pengalaman individu yang terbatas, melainkan melibatkan upaya keras individu yang bersifat interaktif. Dengan demikian pendidikan merupakan tanggung jawab kolektif beberapa pihak untuk bersama-sama menghadirkan sumber daya dan kompetensi terbaik demi meningkatnya kualitas pendidikan. Berbagai hasil penelitian yang menunjukkan belum optimalnya kegiatan kemitraan yang dilaksanakan oleh LPI, seperti partisipasi masyarakat yang bisa dikatakan nihil, ${ }^{13}$ tidak memosisikan masing-masing pihak yang terlibat secara sederajat, ${ }^{14}$ mengarahkan pada pentingnya menghadirkan wacana

\footnotetext{
${ }^{7}$ S. Ali Jadid Al Idrus, "Model Strategi Kemitraan pada Lembaga Pendidikan Islam (Studi Kasus di MAN 2 Mataram)," Palapa 5, no. 2 (2017): 20-37.

${ }^{8}$ Syamsul Arifin, "Kemitraan Sekolah-Masyarakat sebagai Upaya Peningkatan Mutu Pendidikan di Sampang, Jawa Timur," None 8, no. 1 (2012): 11408.

${ }^{9}$ Bullard, McAlister, dan Chilton, "Covid-19: Planning and Postpandemic Partnerships."

${ }^{10}$ Raguindin, Lising, dan Custodio, "Strategies for Parental Involvement during Emergency Remote Teaching Scale: Its Psychometric Properties."

${ }^{11}$ Joyce L. Epstein dkk., School, family, and Community Partnerships: Your Handbook for Action (Corwin Press, 2018), 44.

12 Pokhrel dan Chhetri, "A Literature Review on Impact of Covid-19 Pandemic on Teaching and Learning."

${ }^{13}$ Arifin, "Kemitraan Sekolah-Masyarakat sebagai Upaya Peningkatan Mutu Pendidikan di Sampang, Jawa Timur."

${ }^{14}$ Al Idrus, "Model Strategi Kemitraan pada Lembaga Pendidikan Islam (Studi Kasus di MAN 2 Mataram)."
} 
tentang tema ini untuk memberikan perspektif baru bagi pengelola LPI akan pentingnya kemitraan bagi institusi. Untuk itu, kajian ini menghadirkan wacana pentingnya kemitraan bagi LPI yang menjelaskan tiga hal, yaitu: apakah kemitraan sekolah itu; siapa sajakah yang perlu dilibatkan dalam kemitraan sekolah; dan mengapa perlu dikembangkan kemitraan sekolah pada LPI.

\section{Metode}

Penelitian ini menggunakan metode kajian literatur dengan jenis integrative literature review. Pemilihan jenis kajian ini mengacu pada tujuan penelitian untuk menyintesiskan berbagai literatur tentang topik penelitian yang memungkinkan munculnya perspektif baru. Penelitian ini bertujuan menghadirkan kajian integratif tentang kemitraan sekolah pada konteks lembaga pendidikan Islam, mendasarkan pada kajian-kajian yang sudah mapan untuk kemudian disintesiskan dengan berbagai kajian kemitraan pada konteks lembaga pendidikan Islam. Menurut Snyder integrative literature review dapat digunakan untuk membahas topik yang sudah mapan atau yang baru muncul, di mana untuk topik yang sudah mapan, kajian dimaksudkan untuk melakukan overview terhadap pengetahuan dasar, melakukan kajian kritis, mengonsep ulang hingga mengembangkan konsep yang menjadi dasar. ${ }^{15}$ Bentuk sintesis dari penelitian ini adalah menghasilkan kerangka konsep, yaitu perspektif baru tentang topik yang dikaji secara integratif. ${ }^{16}$ Analisis data pada metode kajian literatur integratif tidaklah dikembangkan berdasarkan pada standar tertentu seperti misalnya pada systematic literature review. ${ }^{17}$ Dengan demikian, pada metode ini, penelitian dapat dilakukan dengan berbagai cara yang memungkinkan tercapainya tujuan penelitian. Meski penelitian dapat dilaksanakan secara fleksibel, Torraco tetap menyarankan agar para peneliti tetap dapat melaporkan langkah-langkah bagaimana studi tersebut dilaksanakan. ${ }^{18}$ Untuk menjaga kredibilitas dari hasil kajian, penelitian ini dilakukan dengan mengikuti kerangka kerja kajian literatur integratif dari Whittemore \& $\mathrm{Knafl}^{19}$ yang terdiri dari lima tahapan: (1) problem identification, (2) literature search, (3) data evaluation; (4) data analysis; (5) presentation. Tabel 1 menunjukkan pelaksanaan tahapan penelitian tersebut.

\footnotetext{
${ }^{15}$ Hannah Snyder, "Literature Review as a Research Methodology: An Overview and Guidelines," Journal of Business Research 104 (2019): 333-39.

16 Richard J. Torraco, "Writing Integrative Literature Reviews: Using the Past and Present to Explore the Future," Human Resource Development Review 15, no. 4 (2016): 404-28.

17 Robin Whittemore dan Kathleen Knafl, "The Integrative Review: Updated Methodology," Journal of Advanced Nursing 52, no. 5 (2005): 546-53.

${ }^{18}$ Richard J. Torraco, "Writing Integrative Literature Reviews: Guidelines and Examples," Human resource Development Review 4, no. 3 (2005): 356-67.

${ }^{19}$ Whittemore dan Knafl, "The Integrative Review: Updated Methodology."
} 


\begin{tabular}{|c|c|}
\hline $\begin{array}{l}\text { Tahapan Kajian } \\
\text { lieratur }\end{array}$ & Pelaksanaan \\
\hline $\begin{array}{l}\text { Problem } \\
\text { indentification }\end{array}$ & $\begin{array}{l}\text { Kajian teoritis dan empiris terdahulu mengarahkan pentingnya kemitraan } \\
\text { yang sistematis bagi lembaga pendidikan. Namun demikian, pelaksanaan di } \\
\text { tingkat lembaga pendidikan Islam lebih sering sebatas retorika, dan jika } \\
\text { dilaksanakan, lebih bersifat episodik dan reaktif. Kajian-kajian tentang } \\
\text { kemitraan di lembaga pendidikan Islam juga didapati masih minim. Padahal, } \\
\text { di tengah pandemi saat ini, kerjasama tidak lagi menjadi aktivitas yang } \\
\text { penting bagi lembaga pendidikan Islam, namun menjadi keharusan demi } \\
\text { tercapainya tujuan pendidikan. Untuk itu, terdapat kebutuhan menghadirkan } \\
\text { kajian integratif tentang kemitraan pada konteks lembaga pendidikan Islam } \\
\text { dengan menganalisis tiga konsep: apa, siapa dan mengapa kemitraan menjadi } \\
\text { harus dilaksanakan secara sistematis oleh lembaga pendidikan Islam. }\end{array}$ \\
\hline Literature Search & $\begin{array}{l}\text { Fokus dari kajian literatur ini adalah kemitraan di lembaga pendidikan Islam } \\
\text { dengan menjawab tiga persoalan: apa itu kemitraan sekolah, siapa saja pihak } \\
\text { yang bisa dilibatkan dalam kemitraan dan mengapa kemitraan menjadi } \\
\text { keharusan bagi lembaga pendidikan Islam. Untuk menjawab persoalan } \\
\text { tersebut, dilakukan pencarian terhadap buku maupun hasil-hasil penelitian } \\
\text { baik secara online maupun offline. Pencarian secara online, dilakukan pada } \\
\text { situs pencarian google scholar dan google web, dengan kata kunci: "school } \\
\text { partnership"; "school collaboration"; "Islamic School Partership" dan } \\
\text { "Islamic school collaboration". Sedangkan pencarian secara offline } \\
\text { dilakukan dengan mencari di perpustakaan terkait dengan buku-buku yang } \\
\text { bertema "manajemen pendidikan". Setelah ditemukan kurang lebih } 92 \\
\text { sumber yang potensial dalam membahas kemitraan di lembaga pendidikan } \\
\text { Islam, selanjutnya dilakukan reduksi dengan lebih memfokuskan pada } \\
\text { sumber yang membahas tiga poin: siapa, apa dan mengapa. Hasilnya dipilih } \\
33 \text { sampel sumber yang relevan untuk diproses menuju tahapan selanjutnya. }\end{array}$ \\
\hline Data Evaluation & $\begin{array}{l}\text { Sampel-sampel yang relevan dari berbagai sumber, tentu sangat beragam } \\
\text { jenisnya. Untuk memudahkan proses selanjutnya, dilakukan evaluasi } \\
\text { terhadap sampel tersebut dengan dua cara: (1) membagi sampel menjadi dua } \\
\text { jenis data saja: Jenis kajian empiris dan jenis kajian teoritis; dan (2) } \\
\text { memberlakukan sistem rating. Sistem rating dilakukan dengan memberikan } \\
\text { skor tinggi hingga rendah pada masing-masing sampel berdasarkan tingkat } \\
\text { relevansinya. }\end{array}$ \\
\hline Data Analysis & $\begin{array}{l}\text { Berdasarkan dua jenis data teroritis dan empiris, data dianalisis mengikuti } \\
\text { langkah penelitian dari Miles dan Huberman: reduction, display; conclusion } \\
\text { drawing and verification. Data terlebih dahulu direduksi dengan melakukan } \\
\text { koding dan kategorisasi, yaitu kategori: pengertian dari kemitraan sekolah; } \\
\text { pihak yang dilibatkan dalam kemitraan dan hasil dari kemitraan. Selanjutnya, } \\
\text { dilakukan display agar dapat dilakukan abstraksi untuk membuat kesimpulan } \\
\text { yang didasarkan atas sumber-sumber utama yang memiliki rating tinggi, } \\
\text { untuk memverifikasi bahwa konsep baru yang dihadirkan telah sesuai dengan } \\
\text { sumber data primer. }\end{array}$ \\
\hline Presentation & $\begin{array}{l}\text { Langkah terakhir adalah melakukan sintesis atas semua data yang telah } \\
\text { diverifikasi dalam sebuah kajian komprehensif tentang kemitraan di lembaga } \\
\text { pendidikan Islam }\end{array}$ \\
\hline
\end{tabular}

Tabel 1. Tahapan Pelaksanaan Penelitian 


\section{Pembahasan}

\section{Mendefinisikan Kemitraan Sekolah}

Menjalin sebuah kemitraan dan bekerjasama adalah hal yang biasa bagi organisasi. Goodlad mendefinisikan kemitraan sebagai sebuah kolaborasi yang dirancang secara sengaja melalui pengaturan antar pihak berbeda, saling bekerjasama untuk memecahkan masalah bersama. ${ }^{20}$ Kemitraan mensyaratkan adanya kerjasama dan hubungan timbal balik yang saling memberikan manfaat. Sirotnik \& Goodlad mempertegas bahwa tujuan dari kemitraan adalah menciptakan proses yang memungkinkan mitra dapat memanfaatkan kelebihan satu sama lain untuk memajukan dan mengembangkan semua pihak. ${ }^{21}$ Dalam konteks pendidikan school partnership melibatkan upaya kolaborasi dan kerjasama sekolah dengan stakeholder lembaga pendidikan. Melalui school partnership, menyatukan dua pihak atau lebih bersama-sama ke dalam sebuah komunitas mitra yang saling memberikan timbal balik. $^{22}$

Kemitraan sekolah dan masyarakat digambarkan sebagai hubungan yang bermakna antara sekolah dengan anggota masyarakat, berbagi tanggung jawab untuk meningkatkan intelektual, sosial, dan emosional peserta didik. ${ }^{23}$ Kelompok-kelompok masyarakat yang dimaksud meliputi organisasi-organisasi, bahkan unit bisnis yang berkomitmen untuk bekerja sama secara kooperatif, baik unit bisnis kecil, nonprofit, bahkan dengan lembaga pendidikan yang lebih besar dan jenjang yang lebih tinggi. Bentuk kemitraan dapat beragam, selama dimaksudkan untuk memenuhi kebutuhan peserta didik. Oleh karena itu, Kemitraan sekolah merupakan upaya pelibatan berbagai pihak yang memiliki kepentingan akan lembaga pendidikan, baik secara langsung maupun tidak langsung, profit maupun nonprofit, berada pada jenjang yang setara, lebih rendah ataupun lebih tinggi. Semua pihak berkolaborasi dan bekerjasama dalam posisi yang saling menguntungkan demi tercapainya tujuan bersama dan maju bersama. Kemitraan dilaksanakan dalam pengaturan tertentu yang disepakati bersama oleh pihak-pihak yang terlibat.

\footnotetext{
${ }^{20}$ John I. Goodlad, "School-university Partnerships and Partner Schools," Educational Policy 7, no. 1 (1993): 24-39.

${ }^{21}$ Kenneth A. Sirotnik dan John I. Goodlad, School-University Partnerships in Action: Concepts, Cases,. (ERIC, 1988).

${ }^{22}$ Donna R. Sanderson, "Working Together to Strengthen the School Community: The Restructuring of a University-school partnership.," School Community Journal 26, no. 1 (2016): 183-98.

${ }^{23}$ Gross, "Strong School-Community Partnerships in Inclusive Schools Are" Part of the Fabric of the School... We Count on Them"."
} 


\section{Aktor-aktor Kemitraan Sekolah}

Menurut Benavot \& Naidoo, dalam upaya menghadapi tuntutan perubahan pada dunia pendidikan perlu adanya kerjasama dan kolaborasi antar elemen pemangku kepentingan dari institusi agar dapat menemukan potensi solusi kreatif yang mengacu pada kekuatan gabungan pemerintah, masyarakat, akademisi, dan sektor swasta. ${ }^{24}$ Membangun jaringan dan melakukan kolaborasi akan sangat bermanfaat bagi perkembangan sekolah. Peran serta masyarakat dalam pendidikan dapat meliputi peran serta perseorangan, kelompok, keluarga, organisasi profesi, pengusaha, dan organisasi kemasyarakatan. Masyarakat dapat berperan serta, baik sebagai sumber, pelaksana, dan pengguna hasil pendidikan. ${ }^{25}$ Kolaborasi melibatkan stakeholder di lingkungan internal maupun lingkungan eksternal sekolah.

Terdapat dua lingkungan yang berpengaruh baik secara langsung maupun tidak langsung pada Lembaga Pendidikan Islam (LPI) sebagai sebuah sistem terbuka, yaitu lingkungan internal dan lingkungan eksternal. Kedua lingkungan tersebut memiliki kelompok-kelompok yang berperan memengaruhi kelangsungan hidup lembaga. Kelompokkelompok yang berkepentingan atas lembaga inilah yang selanjutnya disebut dengan stakeholder. Sallis menyebutkan stakeholder sebuah lembaga pendidikan yang menjadi pelanggan internal dan pelanggan eksternal. ${ }^{26}$ Pelanggan internal terdiri dari guru dan staf, sedangkan pelanggan eksternal terdiri dari pelanggan eksternal utama yaitu: peserta didik, dan pelanggan eksternal lainnya: orang tua, kepala daerah, sponsor, pemerintah, masyarakat serta dunia kerja. Beberapa kelompok yang turut berkepentingan dengan lembaga seperti: kompetitor, pelanggan, suplier, intermediaris dan publik lainnya. ${ }^{27}$ Masing-masing pihak tersebut berinteraksi satu sama lain, tidak hanya berpengaruh pada lembaga pendidikan, tetapi juga menciptakan kondisi situasi yang turut berpengaruh pada respon elemen-elemen yang ada.

Terdapat dua kelompok stakeholder yang perlu diidentifikasi oleh LPI dalam mengembangkan kemitraan, yaitu stakeholder internal dan eksternal. Dalam kemitraan sekolah, lembaga perlu mengidentifikasi masing-masing kelompok pada kedua stakeholder yang tentu berdampak pada kelangsungan hidup lembaga. Skema 1 menunjukkan

\footnotetext{
24 Aaron Benavot dan Jordan Naidoo, "A New Era for Education in the Global Development Agenda," Childhood Education 94, no. 3 (2018): 10-15.

${ }^{25}$ Presiden Republik Indonesia, Undang-Undang Republik Indonesia Nomor 20 Tahun 2003 tentang Sistem Pendidikan Nasional (Jakarta, 2003), pasal 54 ayat 1 dan 2.

${ }^{26}$ Edward Sallis, Total Quality Management in Education (Yogyakarta: IRCiSoD, 2012), 67-71.

${ }^{27}$ Ian G. Evans, Marketing for Schools. (ERIC, 1995), 16.
} 
identifikasi stakeholder, di mana kemitraan dapat dikembangkan dengan semua elemenelemen tersebut.

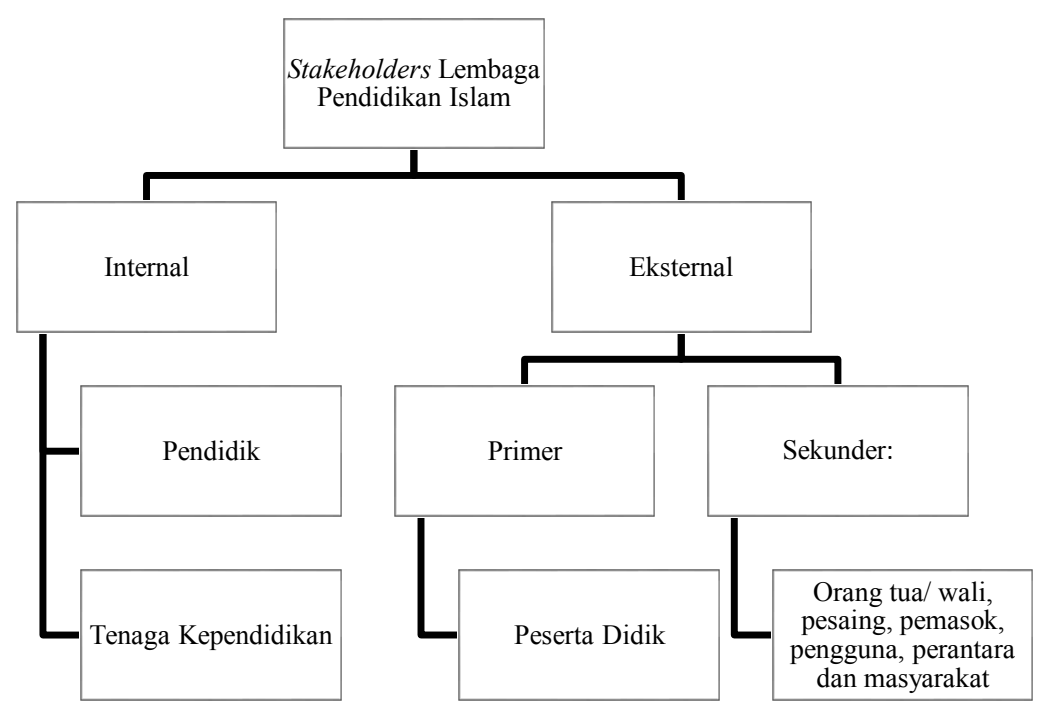

Skema 1. Stakeholder Lembaga Pendidikan Islam

Bullard, McAlister, dan Chilton menunjukkan dua kelompok yang secara mendetail terlibat dalam perkembangan peserta didik, yaitu pendidik dan orang tua. ${ }^{28}$ Strategi pengembangan kemitraan antara keluarga-sekolah dibahas sebagai cara penting dan cara yang layak untuk mendukung peningkatan kemajuan belajar peserta didik. Menurut Lehmann, kemitraan antara keluarga dan sekolah telah menjadi bagian proyek penting yang perlu disiapkan untuk semakin meningkatkan partisipasi masyarakat dalam pendidikan. ${ }^{29}$ Keterlibatan orang tua juga menjadi kunci sukses pelaksanaan program-program di sekolah. Hasil kajian Povey menunjukkan adanya kesimpulan bahwa telah banyak kajian yang membuktikan hasil belajar peserta didik optimal tergantung pada dua faktor kunci yaitu orang tua dan sekolah. ${ }^{30}$ Bahkan keterlibatan orang tua di sekolah memiliki hubungan tidak langsung yang signifikan terhadap hasil akademik dan kesehatan mental peserta didik. ${ }^{31}$ Diperlukan langkah-langkah praktis yang efektif dan efisien untuk menggerakkan orang tua atau keluarga untuk memberikan dukungan bagi pembelajaran di rumah. Kolaborasi sekolah yang sesungguhnya dapat terwujud hanya melalui kemitraan yang aktif dan positif dengan

\footnotetext{
${ }^{28}$ Bullard, McAlister, dan Chilton, "Covid-19: Planning and Postpandemic Partnerships."

29 Jürgen Lehmann, "Parental Involvement: An Issue for Swiss Primary School Teacher Education,” Journal of Education for Teaching 44, no. 3 (2018): 296-308.

30 Jenny Povey dkk., "Engaging Parents in Schools and Building Parent-School Partnerships: The Role of School and Parent Organisation Leadership," International Journal of Educational Research 79 (2016): 12841.

${ }^{31}$ Ming-Te Wang dan Salam Sheikh- Khalil, "Does Parental Involvement Matter for Student Achievement And Mental Health in High School?," Child Development 85, no. 2 (2014): 610-25.
} 
keluarga. ${ }^{32}$ Menciptakan kemitraan antara sekolah dan keluarga merupakan cara penting untuk meningkatkan pembelajaran akademik, sosial, dan emosional peserta didik. ${ }^{33}$ Kolaborasi antara orang tua dan sekolah dapat memperluas pembelajaran siswa melalui pengaturan yang konsisten dan koheren antara ruang kelas dengan lingkungan rumah.

Salah satu sarana yang dapat digunakan untuk mendukung terciptanya kolaborasi antara orang tua dengan anak adalah melalui penggunaan IT dalam pendidikan. Hasil penelitian Kong \& Li menunjukkan bahwa kerjasama antara orang tua dan sekolah dalam upaya memperluas pembelajaran siswa dalam memanfaatkan IT membawa dua implikasi yakni bagi orang tua dan sekolah. ${ }^{34}$ Implikasi pertama menyangkut peran orang tua, di mana orang tua perlu memiliki persepsi positif tentang penggunaan IT dan sangat mendukung pembelajaran anak-anak mereka melalui IT di rumah. Sekolah perlu membantu mereka mengatasi kekhawatiran mereka tentang hal-hal yang tidak patut dalam penggunaan IT oleh anak-anak mereka. Implikasi kedua adalah untuk kesuksesan kolaborasi sekolah-orang tua atau keluarga, diperlukan kesiapan orang tua atau keluarga untuk menyediakan fasilitas IT yang dibutuhkan, sekaligus memberikan edukasi kepada anak-anak atas penggunaan IT dalam proses pendidikan.

Masyarakat lembaga pendidikan merupakan kelompok-kelompok yang melingkupi dan berpengaruh pada institusi pendidikan, termasuk kelompok pesaing. Pesaing dalam konteks pendidikan dapat diartikan sebagai alternatif lain yang dapat diraih peserta didik dalam hal pendidikan. ${ }^{35}$ Artinya, pesaing dalam konteks ini dapat dimaknai sebagai lembaga sejenis, pada jenjang yang sama. Bahkan terhadap pesaing, lembaga pendidikan juga perlu mengembangkan kemitraan yang saling menguntungkan bagi masing-masing lembaga. Studi Kong menjelaskan bagaimana kemitraan antar sekolah dapat menghasilkan manfaat dalam pengembangan suatu program e-learning. Hasil dari penelitian mengungkapkan bahwa kebijakan dalam hal mendukung terbentuknya kelompok mitra sekolah untuk-sama membangun platform berbagi secara online sangat bermanfaat dalam mendorong para guru untuk saling memberi dan menerima dalam lingkungan ekologi yang dinamis dan lingkungan berkelanjutan untuk pengembangan e-learning. Meski menjadi pesaing, beberapa bentuk strategi pengembangan kemitraan dapat tetap dijalin untuk tujuan kemajuan

\footnotetext{
32 Lawrence J. Johnson, Marleen C. Pugach, dan Annie Hawkins, "School-family Collaboration: A Partnership," Focus on Exceptional Children 36, no. 5 (2004): 1.

${ }^{33}$ Christenson, "The Family-School Partnership: An Opportunity To Promote The Learning Competence of All Students."

${ }^{34}$ Siu Cheung Kong dan Kai Ming Li, "Collaboration Between School and Parents to Foster Information Literacy: Learning in the Information Society," Computers \& Education 52, no. 2 (2009): 275-82.

${ }^{35}$ Evans, Marketing for Schools., 17.
} 
institusi, antara lain: (1) Kerjasama dalam mengadakan kompetisi bersama antar sekolah; (2) Kerjasama dalam mengembangkan ekstrakurikuler khusus; (3) Kerjasama dalam melaksanakan program sekolah. ${ }^{36}$

Pemasok merupakan pihak yang memberikan input ke organisasi. Input dapat berupa bahan baku, bahan setengah jadi, karyawan, modal keuangan, informasi, atau jasa yang diperlukan organisasi. Dalam konteks pendidikan, yang menjadi salah satu kelompok pemasok adalah lembaga pendidikan dengan jenjang yang lebih rendah, di samping pemasok furnitur, agen buku, kantor periklanan, dan lembaga outsourcing. Penting bagi sekolah untuk bermitra dengan perguruan tinggi. ${ }^{37}$ Lembaga pendidikan tidak hanya perlu berkolaborasi dengan lembaga pendidikan lain yang sederajat, namun juga dengan lembaga pada jenjang di bawah atapun di atasnya. Bentuk kemitraan yang dapat dikembangkan LPI dengan kelompok pemasok yaitu: pemberian beasiswa prestasi bagi peserta didik kelompok pemasok; kunjungan antar lembaga dalam rangka sosialisasi dan pengenalan; dan mengundang kelompok pemasok pada open house. Kemitraan antar sekolah lokal ataupun sekolah yang lebih baik pada jangka panjang akan menaikkan prestasi akademik. ${ }^{38}$

Pengguna adalah individu atau kelompok yang menggunakan produk hasil atau output dari organisasi. Dalam konteks pendidikan, pengguna adalah pihak yang menggunakan lulusan dari lembaga pendidikan tersebut. Pengguna meliputi lembaga pendidikan yang berada pada jenjang lebih tinggi ataupun dunia kerja atau kelompok bisnis yang menyerap lulusan lembaga pendidikan. Bentuk kemitraan yang dibangun dengan pengguna dapat berupa benchmarking, visitasi dalam kegiatan hubungan masyarakat, ataupun kolaborasi dalam pelaksanaan kejuaraan atau program-program tertentu. Kemitraan dengan dunia kerja secara umum ataupun kelompok pengguna lulusan akan turut berdampak pada turut berkembangnya potensi peserta didik, menyesuaikan dengan kebutuhan pasar serta kebutuhan menjawab tantangan zaman.

Sebagai bagian dari masyarakat, kelompok bisnis merupakan stakeholder yang juga memiliki kepentingan atas efektivitas sekolah. ${ }^{39}$ Di samping organisasi bisnis, pemerintah dan berbagai komunitas tertentu juga termasuk pada kelompok masyarakat. Kemitraan

\footnotetext{
${ }^{36}$ Siu Cheung Kong, "Partnership among Schools in e-Learning Implementation: Implications on Elements for Sustainable Development," Journal of Educational Technology \& Society 22, no. 1 (2019): 28-43.

${ }^{37}$ Mellita Jones Dkk., "Successful University-School Partnerships: An Interpretive Framework To Inform Partnership Practice," Teaching And Teacher Education 60 (2016): 108-20.

${ }^{38}$ Jorge P. Osterling dan Armandina Garza, "Strengthening Latino Parental Involvement Forming CommunityBased Organizations/School Partnership," NABE Journal of Research and Practice 2, no. 1 (2004): 270-84.

${ }^{39}$ Kevin Badgett, "School-Business Partnerships: Understanding Business Perspectives.," School Community Journal 26, no. 2 (2016): 83-105.
} 
dengan pihak pemerintah maupun pusat dimaksudkan untuk terus menginformasikan tentang regulasi dan kebijakan baik yang berkaitan secara langsung maupun tidak langsung dengan dunia pendidikan. Kemitraan dapat diwujudkan dalam bentuk melibatkan pemerintah sebagai tenaga ahli yang melakukan supervisi pendidikan. Komunitas yang ada di dalam masyarakat juga memiliki dampak secara langsung maupun tidak langsung pada lembaga pendidikan. Maka perlu terus dikembangkan berbagai program yang melibatkan kolaborasi komunitas-komunitas tersebut dengan Lembaga Pendidikan Islam, sebagai bentuk keterlibatan dan menumbuhkan sense of belonging.

\section{Urgensi Kemitraan Sekolah bagi Lembaga Pendidikan Islam (LPI)}

Konsep kemitraan melibatkan konsep-konsep lain seperti kolaborasi dan kerja sama yang dimaknai sebagai bekerja secara bersama-sama. Konsep yang sama juga dikembangkan di dalam Islam yaitu al ta'awwun atau bergotong royong dan bekerjasama saling tolongmenolong. Kebutuhan manusia sangatlah banyak di luar kemampuan manusia untuk memenuhinya sendiri dan membutuhkan pihak lain agar dapat terpenuhi, maka perlu ta'awwun antara pihak satu dengan pihak yang lain. ${ }^{40}$ Dalam konsep bekerja sama, masingmasing pihak memiliki fungsi dan perannya sendiri. Dengan demikian salah satu pihak tidak dapat menafikan eksistensi pihak lainnya, dengan kata lain posisinya adalah setara.

Kemitraan sekolah dan masyarakat memainkan peran penting dalam kesuksesan sebuah sekolah. ${ }^{41}$ Melalui kemitraan akan diupayakan untuk memberikan pendidikan terbaik yang mungkin diberikan pada peserta didik dan masyarakat. Alasan utama menciptakan kemitraan adalah membantu peserta didik sukses di sekolah dan di kehidupannya kelak. ${ }^{42}$ Kemitraan ini muncul dalam rangka peningkatan hubungan masyarakat, memunculkan sumber pendanaan tambahan, ataupun upaya untuk penanggulangan atas berbagai permasalahan yang muncul. Kemitraan dapat mengembangkan program dan iklim sekolah, penyedia layanan dan dukungan keluarga, meningkatkan kepemimpinan dan keahlian orang tua, menghubungkan antar keluarga dan komunitas di sekolah, serta membantu pendidik dalam pekerjaannya. ${ }^{43}$

\footnotetext{
${ }^{40}$ Muhammad Djakfar, Wacana Teologi Ekonomi: Membumikan Titah Langit di Ranah Bisnis dalam Era Globalisasi (UIN-Maliki Press, 2015), 131.

${ }^{41}$ Gross, "Strong School-Community Partnerships in Inclusive Schools Are" Part of the Fabric of the School... We Count on Them"."

${ }^{42}$ Epstein dkk., School, Family, and Community Partnerships: Your Handbook for Action, 20.

${ }^{43}$ Epstein dkk., 20.
} 
School partnership yang melibatkan keluarga dan masyarakat luas misalnya akan berdampak pada meningkatnya motivasi belajar dan atmosfer sekolah yang lebih positif. Sekolah yang mengembangkan kemitraan yang kuat menunjukkan adanya: peningkatan prestasi, peningkatan keterlibatan orang tua secara sukarela, peningkatan angka kedatangan siswa di sekolah. ${ }^{44}$ Penelitian secara sistematis menggambarkan bahwa keterlibatan keluarga, dan kelompok masyarakat pada pendidikan berpengaruh kuat terhadap prestasi peserta didik. ${ }^{45}$ Kemitraan juga akan mengurangi kemungkinan miscommmunication dan misunderstanding di antara stakeholder dalam pendidikan. Untuk dapat mengembangkan school partnership memang diperlukan usaha dan waktu, namun ketika sudah berkembang serta berkelanjutan maka manfaat terus menerus akan diperoleh individu maupun kelompok dalam pendidikan. LPI merupakan salah satu organisasi jasa. Organisasi dimaknai sebagai wadah, badan, atau tempat berkumpulnya dua orang atau lebih untuk bekerja sama dalam mencapai tujuan tertentu. Dalam organisasi, terdapat sekelompok orang yang saling berinteraksi untuk merealisasikan tujuan bersama secara efektif dan efisien. Efektif berarti membuat keputusan dengan tepat dan mengimplementasikannya dengan sukses, sedangkan efisien berarti menggunakan berbagai sumber daya secara bijaksana dan dengan cara yang hemat biaya.

Pemahaman tentang makna organisasi tersebut mengarahkan pada asumsi bahwa organisasi dapat lahir dan berkembang karena: (1) ada interaksi antara satu dengan yang lain; (2) ada kerja sama dari berbagai pihak; (3) ada tujuan bersama yang ingin dicapai; dan (4) ada cara pencapaian secara efektif dan efisien. Keempat unsur tersebut menjadi prasyarat yang perlu ada dalam pengelolaan organisasi, termasuk juga pada institusi pendidikan. Salah satu poin penting dari keempat unsur tersebut adalah adanya kerjasama dari berbagai pihak untuk menyukseskan tercapainya tujuan institusi. LPI sebagai sebuah sistem sosial, terdiri atas elemen-lemen yang saling berinteraksi, ${ }^{46}$ dan dibentuk atas dasar kepentingan bersama. $^{47}$

Elemen-elemen organisasi tersebut saling tergantung, terkoneksi dan berhubungan, sebagai satu kesatuan yang utuh. Dengan demikian kesuksesan LPI akan sangat bergantung pada kemitraan dengan kolaborasi dari semua elemen organisasi yang saling terhubung. LPI

\footnotetext{
${ }^{44}$ Gross, "Strong School-Community Partnerships in Inclusive Schools Are" Part of the Fabric of the School... We Count on Them"."

45 Osterling dan Garza, "Strengthening Latino Parental Involvement Forming Community-based Organizations/School Partnership."

${ }^{46}$ French Wendell L. dan Cecil H. Bell Jr., Organizational Development: Behavior Science Interviews for Organization Improvement (Upper Saddle River: Prentice Hall, 1999), 18.

${ }^{47}$ Davis Keith dan Jhon W. Newstrom, Perilaku dalam Organisasi (Jakarta: Erlangga, 1995), 5.
} 
perlu mengembangkan kemitraan dengan semua stakeholder demi kelangsungan hidup organisasi. Setidaknya, terdapat tiga alasan pentingnya pengembangan kemitraan pada LPI: (1) Sustainability; (2) good governance; dan (3) quality improvement.

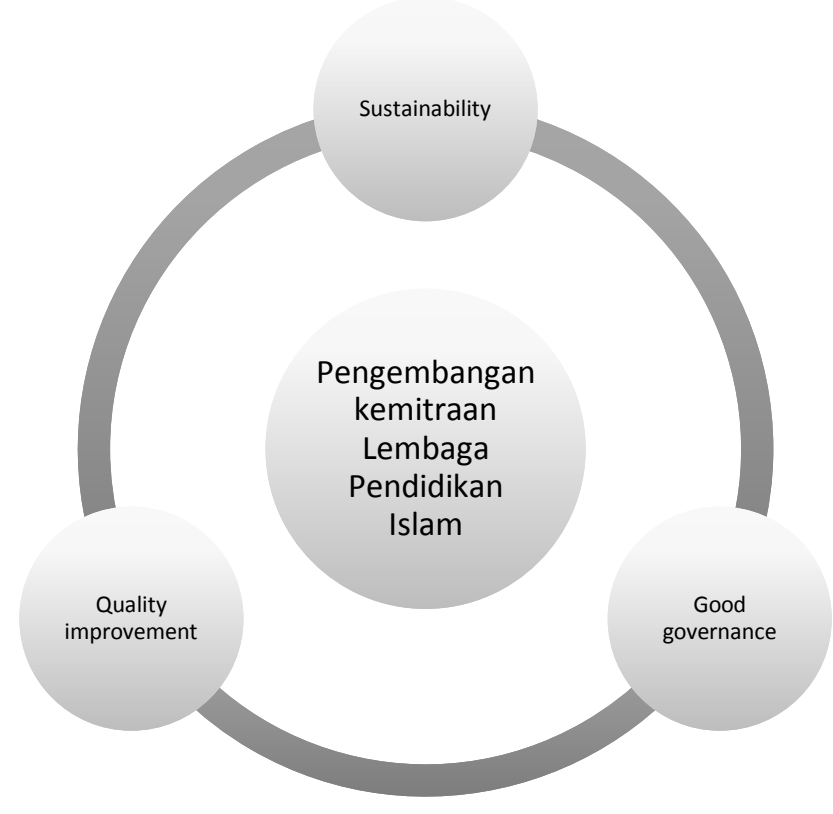

Gambar 2. Urgensi Pengembangan Kemitraan bagi Lembaga Pendidikan Islam

\section{Keberlangsungan hidup lembaga (Sustainability)}

Lembaga Pendidikan Islam (LPI) sebagai industri jasa mengarahkan pada pandangan bahwa institusi layaknya sebuah korporasi yang menghasilkan jasa pendidikan yang dibeli oleh para stakeholdernya. ${ }^{48}$ Alma mengatakan bahwa lembaga pendidikan pada hakikatnya memberikan layanan. Seperti layaknya organisasi korporasi lainnya, LPI saling bersaing memproduksi dan memasarkan memasarkan layanan-layanan pendidikan, untuk dapat dipilih oleh masyarakat. Lembaga Pendidikan tidak terlepas dari konsep persaingan yang menuntut lembaga agar dapat memberikan layanan yang terbaik sehingga menjadi pilihan masyarakat. ${ }^{49}$ Dengan demikian keberlangsungan hidup lembaga dapat terjaga.

Evans menyatakan bahwa pendidikan juga merupakan sebuah pasar di mana di dalamnya juga terdapat hukum permintaan dan penawaran. Dalam pasar pendidikan, di mana lembaga merupakan satu bagian yang di dalamnya terdapat banyak penyedia dan konsumen layanan pendidikan. Saat ini konsumen layanan pendidikan dapat memilih lembaga yang mereka suka. Meskipun dalam praktiknya, pendidikan bukan merupakan sebuah pasar

\footnotetext{
48 Buchari Alma, "Pemasaran Jasa Pendidikan yang Fokus Pada Mutu," dalam Manajemen Corporate \& Strategi Pemasaran Jasa Pendidikan: Fokus Pada Mutu dan Layanan Prima, ed. oleh Buchari Alma dan Ratih Hurriyati (Bandung: Alfabeta, 2009), 13.

${ }^{49}$ Buchari Alma, Pemasaran Stratejik Jasa Pendidikan (Bandung: Alfabeta, 2005), 46.
} 
persaingan sebagaimana yang terjadi dalam dunia korporasi, namun ada satu hal yang menjadikannya mirip dengan sebuah pasar korporasi adalah bahwa konsumen pendidikan berhak memilih lembaga yang mereka inginkan, serta lembaga penyedia layanan pendidikan tidaklah memiliki kontrol sepenuhnya akan pasar yang ada. ${ }^{50}$

Untuk dapat memenangkan persaingan merebut hati para orang tua, LPI harus mampu menyediakan layanan pendidikan yang sesuai dengan kebutuhan mereka. Pengembangan kemitraan dengan para stakeholder LPI menjadi penting dalam upayanya agar lembaga senantiasa meningkatkan layanan yang diberikan mengikuti kebutuhan pasar. LPI dapat mengidentifikasi para stakeholder yang dapat berpengaruh besar pada pengembangan lembaga, serta mengupayakan pengembangan kemitraan dengan pihak-pihak tersebut dalam berbagai bentuk kolaborasi. Stakeholder pendidikan merupakan pihak-pihak yang berkepentingan dengan lembaga, yang memiliki potensi besar untuk ikut mendorong kesuksesan lembaga di masa sekarang dan masa mendatang.

\section{Tata Kelola yang Baik (Good Governance)}

Lembaga pendidikan sebagai industri penyedia jasa memiliki karakteristik: output-nya bukan berupa produk yang tampak secara fisik, dikonsumsi bersamaan dengan waktu produksi, dan memberikan nilai tambah. ${ }^{51}$ Lembaga menghasilkan jasa atau layanan pendidikan yang disajikan kepada pelanggannya, terutama dalam hal ini adalah peserta didik. ${ }^{52}$ Penyebutan industri sebab di dalamnya terdapat kegiatan sebagaimana sebuah sistem yang memproses input-sumber daya manusia, peserta didik, sarana prasarana, keuangan dan sebagainya-menjadi output yaitu berupa penambahan nilai dan kompetensi peserta didik.

Meski merupakan lembaga nonprofit yang memiliki tujuan berbeda dengan korporasi yang bersifat mencari laba, namun LPI tetap saja membutuhkan pengelolaan dengan sistem tata kelola yang baik. Persaingan menuntut lembaga untuk memiliki good governance agar dapat menghasilkan produk yang berkualitas dan menjadi lembaga yang efektif dan efisien. Pada akhirnya, lembaga dapat menjadi pilihan masyarakat karena kemampuannya dalam menghasilkan output berkualitas melalui tata kelolanya yang baik.

Keberadaan LPI, baik yang berbentuk madrasah, beberapa memang belum sepenuhnya sesuai dengan apa yang diharapkan umat. Namun beberapa madrasah yang memiliki tata

\footnotetext{
${ }^{50}$ Evans, Marketing for Schools., 12.

${ }^{51}$ V. A. Zeithaml dan M. J. Bitner, Services Marketing: Integrating Customer Focus Across the Firm (Boston: Irwin/McGraw-Hill, 2000), 3.

52 Daulat Purnama Tampubolon, Perguruan Tinggi Bermutu: Paradigma Baru Manajemen Pendidikan Tinggi Menghadapi Tantangan Abad Ke-21 (Gramedia Pustaka Utama, 2001), 69-71.
} 
kelola yang baik telah menjadi pilihan utama orang tua di Indonesia yang mayoritas adalah muslim, sebab mampu menjawab kebutuhan akan output yang tidak hanya memiliki kematangan intelektual namun juga kematangan mental dan spiritual. ${ }^{53}$ Hal ini ditunjukkan dengan menguatnya fenomena masyarakat untuk menyekolahkan anak mereka pada madrasah atau sekolah Islam, seperti MI, SDI, Islamic Boarding School, Pesantren. Kenyataan ini sejalan dengan pendapat Qomar yang menyatakan bahwa kebutuhan masyarakat muslim kelas menengah ke atas sekarang ini adalah terjaminnya mutu akademik dan kepribadian, terutama dalam menghadapi era globalisasi. Kualitas saat ini telah menjadi tuntutan masyarakat. Untuk itu, LPI membutuhkan pengembangan kemitraan dengan berbagai pemangku kepentingan yang ikut mendorong terwujudnya good governance lembaga. ${ }^{54}$

Peran strategis LPI dan kemitraanya dengan masyarakat adalah dalam rangka mewujudkan good governance dan pengembangan sosial. ${ }^{55}$ Dikatakan stategis sebab untuk mewujudkan tata kelola yang baik dibutuhkan sinergi peran serta tiap unsur yang berpengaruh pada institusi dalam mewujudkan kepentingan bersama, termasuk dalam konteks ini peran LPI sebagai bagian dari civil society. LPI harus menjadi lembaga yang tetap bisa bertahan dan mampu menjalankan perannya sebagai bagian dari perkembangan pendidikan nasional.

\section{Peningkatan Mutu Lembaga (Quality Improvement)}

Saat ini kualitas pendidikan menjadi kebutuhan dan tuntutan masyarakat. Untuk dapat meraih kesuksesan dalam peningkatan mutu, pemerintah menetapkan jenis pengelolaan pendidikan pada jenjang dasar dan menengah dengan prinsip Manajemen Berbasis Sekolah (MBS) yang mendasarkan pada prinsip otonomi pengelolaan pendidikan. Ketentuan ini tertuang dalam UU Nomor 20 tahun 2003, yang menyatakan: "Pengelolaan satuan pendidikan pada jenjang pendidikan dasar dan menengah menerapkan manajemen berbasis sekolah (MBS) yang ditunjukkan dengan kemandirian, kemitraan, partisipasi, keterbukaan, dan akuntabilitas." 56

\footnotetext{
${ }^{53}$ Faridah Alawiyah, "Pendidikan Madrasah di Indonesia," Aspirasi: Jurnal Masalah-masalah Sosial 5, no. 1 (2014): 51-58.

${ }^{54}$ Mujamil Qomar, Strategi Baru Pengelolaan Lembaga Pendidiakan Islam-Manajemen Pendidikan Islam (Jakarta: Erlangga, 2007), 46.

${ }^{55}$ Asep Kurniawan, "Manajemen Kerjasama Lembaga Pendidikan Islam dengan Masyarakat (Studi Kasus Pondok Pesantren Alam Internasional Saung Balong al-Barokah Cisambeng Palasah Majalengka)," Holistik 15, no. 1 (2016).

${ }^{56}$ Indonesia, Undang-Undang Republik Indonesia Nomor 20 Tahun 2003 Tentang Sistem Pendidikan Nasional, pasal 49 ayat 1.
} 
MBS merupakan sebuah konsep yang dipilih pemerintah di era desentralisasi saat ini sebagai alternatif dalam rangka peningkatan kualitas pendidikan dan persekolahan, yaitu memberikan otonomi yang luas di tingkat sekolah serta partisipasi masyarakat yang tinggi dalam kerangka kebijakan pendidikan nasional. Konsep MBS ini telah lebih dahulu diterapkan di negara-negara lain dengan sebutan yang beragam antara lain self-managing school, collaborative school management, school based management atau community based school management. ${ }^{57}$ Dapat dipahami dari berbagai istilah tersebut bahwa pengelolaan sekolah diarahkan pada partisipasi, kolaborasi, dan kemitraan dengan masyarakat ataupun komunitas lokal dalam upaya pengembangan lembaga pendidikan. Dalam konsep MBS sekolah dituntut untuk lebih mandiri (otonom), lebih mampu membangun hubungan kemitraan dengan dan memperkuat partisipasi stakehoder lembaga, bersikap lebih terbuka dan akuntabel. Dengan demikian pengembangan kemitraan sekolah menjadi bagian penting dari lembaga dalam upaya meningkatakan kualitas sesuai harapan masyarakat.

\section{Penutup}

Hasil kajian ini mengarahkan pada kesimpulan bahwa kemitraan dapat dimaknai sebagai sebuah kolaborasi yang dirancang secara sengaja melalui pengaturan antar pihakpihak yang berbeda, bekerja sama untuk memecahkan masalah bersama. Pemahaman ini mengarahkan pada syarat kemitraan adalah adanya kerjasama dan hubungan timbal balik yang saling memberikan manfaat satu sama lain. Dalam hal ini, lembaga pendidikan perlu mengidentifikasi dua kelompok stakeholder dalam mengembangkan kemitraan, yaitu stakeholder internal dan eksternal. Tidak hanya sebatas pada pemaknaan konsep dan penetapan kelompok stakeholder yang terlibat dalam school partnership. Kajian ini juga mengungkapkan benefit yang akan dicapai lembaga pendidikan ketika menerapkan kemitraan. Setidaknya, terdapat tiga alasan pentingnya pengembangan kemitraan pada lembaga pendidikan Islam dengan para stakeholder-nya: (1) sustainability; (2) good governance; dan (3) quality improvement.

Hasil penelitian berimplikasi pada saran bagi lembaga pendidikan Islam agar dapat memahami pentingnya kemitraan yang memberikan timbal balik. Kemitraan yang terjalin dengan stakeholder hendaknya tidak hanya bersifat retoris, episodik, dan reaktif. Namun dapat dilaksanakan secara sistematis, kontinyu, dan memberikan kemanfaatan kedua belah pihak demi tercapainya tujuan pendidikan. Dengan perspektif yang dihadirkan pada kajian

57 Prim Masrokan Mutohar dan Manajemen Mutu Sekolah, "Strategi Peningkatan Mutu dan Daya Saing Lembaga Pendidikan Islam,” Jogjakarta: Ar-Ruzz Media, 2013, 124. 
ini, diharapkan dapat menjadi dasar bagi penelitian selanjutnya untuk mengungkap berbagai hambatan yang menyebabkan tidak berjalannya kegiatan kemitraan yang sistematis dan saling memberikan manfaat bagi antar pihak yang berkepentingan dengan lembaga pendidikan Islam. Penelitian ini terbatas pada kajian literatur integratif yang menyintesiskan berbagai kajian terdahulu dengan tujuan memungkinkannya muncul perspektif baru. Dengan demikian hasil penelitian ini terbatas atas perspektif baru yang masih perlu kajian mendalam lebih lanjut.

\section{Daftar Rujukan}

Al Idrus, S. Ali Jadid. "Model Strategi Kemitraan pada Lembaga Pendidikan Islam (Studi Kasus di MAN 2 Mataram).” Palapa 5, no. 2 (2017): 20-37.

Alawiyah, Faridah. "Pendidikan Madrasah di Indonesia." Aspirasi: Jurnal MasalahMasalah Sosial 5, no. 1 (2014): 51-58.

Alma, Buchari. "Pemasaran Jasa Pendidikan yang Fokus Pada Mutu." dalam Manajemen Corporate \& Strategi Pemasaran Jasa Pendidikan: Fokus Pada Mutu dan Layanan Prima, disunting oleh Buchari Alma dan Ratih Hurriyati. Bandung: Alfabeta, 2009.

_. Pemasaran stratejikjasa pendidikan. Bandung: Alfabeta, 2005.

Arifin, Syamsul. "Kemitraan Sekolah-Masyarakat sebagai Upaya Peningkatan Mutu Pendidikan di Sampang, Jawa Timur.” None 8, no. 1 (2012): 11408.

Badgett, Kevin. "School-Business Partnerships: Understanding Business Perspectives." School Community Journal 26, no. 2 (2016): 83-105.

Benavot, Aaron, dan Jordan Naidoo. "A New Era for Education in the Global Development Agenda." Childhood Education 94, no. 3 (2018): 10-15.

Bullard, Jodi S., Barbara S. McAlister, dan Jenifer M. Chilton. "Covid-19: Planning and Postpandemic Partnerships.” NASN School Nurse 36, no. 2 (2021): 80-84.

Christenson, Sandra L. "The Family-school Partnership: An Opportunity to Promote the Learning Competence of All Students." School Psychology Review 33, no. 1 (2004): 83-104.

Djakfar, Muhammad. Wacana Teologi Ekonomi: Membumikan Titah Langit di Ranah Bisnis dalam Era Globalisasi. UIN-Maliki Press, 2015.

Epstein, Joyce L., Mavis G. Sanders, Steven B. Sheldon, Beth S. Simon, Karen Clark Salinas, Natalie Rodriguez Jansorn, Frances L. Van Voorhis, Cecelia S. Martin, Brenda G. Thomas, dan Marsha D. Greenfeld. School, Family, and Community Partnerships: Your Handbook for Action. Corwin Press, 2018.

Evans, Ian G. Marketing for Schools. ERIC, 1995.

Gross, Judith. "Strong School-Community Partnerships in Inclusive Schools Are" Part of the Fabric of the School... We Count on Them"." School Community Journal 25, no. 2 (2015): 9-34.

Indonesia, Presiden Republik. Undang-Undang Republik Indonesia Nomor 20 Tahun 2003 Tentang Sistem Pendidikan Nasional. Jakarta, 2003. 
Johnson, Lawrence J., Marleen C. Pugach, dan Annie Hawkins. "School-family Collaboration: A Partnership." Focus on Exceptional Children 36, no. 5 (2004): 1.

Jones, Mellita, Linda Hobbs, John Kenny, Coral Campbell, Gail Chittleborough, Andrew Gilbert, Sandra Herbert, dan Christine Redman. "Successful University-school Partnerships: An Interpretive Framework to Inform Partnership Practice." Teaching and Teacher Education 60 (2016): 108-20.

Kong, Siu Cheung. "Partnership among Schools in e-Learning Implementation: Implications on Elements for Sustainable Development." Journal of Educational Technology \& Society 22, no. 1 (2019): 28-43.

Kong, Siu Cheung, dan Kai Ming Li. "Collaboration between School and Parents to Foster Information Literacy: Learning in the Information Society." Computers \& Education 52, no. 2 (2009): 275-82.

Kurniawan, Asep. "Manajemen Kerjasama Lembaga Pendidikan Islam dengan Masyarakat (Studi Kasus Pondok Pesantren Alam Internasional Saung Balong al-Barokah Cisambeng Palasah Majalengka).” Holistik 15, no. 1 (2016).

Lehmann, Jürgen. "Parental Involvement: An issue for Swiss Primary School Teacher Education." Journal of Education for Teaching 44, no. 3 (2018): 296-308.

Mutohar, Prim Masrokan, dan Manajemen Mutu Sekolah. "Strategi Peningkatan Mutu dan Daya Saing Lembaga Pendidikan Islam.” Jogjakarta: Ar-Ruzz Media, 2013.

Osterling, Jorge P., dan Armandina Garza. "Strengthening Latino Parental Involvement Forming Community-Based Organizations/School Partnership." NABE Journal of Research and Practice 2, no. 1 (2004): 270-84.

Pang, I.-wah. "School-Family-Community Partnership in Hong Kong-Perspectives and Challenges." Educational Research for Policy and Practice 3, no. 2 (2004): 109-25.

Pokhrel, Sumitra, dan Roshan Chhetri. "A Literature Review on impact of Covid-19 Pandemic on Teaching and Learning." Higher Education for the Future 8, no. 1 (2021): 133-41.

Povey, Jenny, Alice Kate Campbell, Linda-Dianne Willis, Michele Haynes, Mark Western, Sarah Bennett, Emma Antrobus, dan Charley Pedde. "Engaging Parents in Schools and Building Parent-School Partnerships: The Role of School and Parent Organisation Leadership.” International Journal of Educational Research 79 (2016): $128-41$.

Qomar, Mujamil. Strategi Baru Pengelolaan Lembaga Pendidikan Islam-Manajemen Pendidikan Islam. Jakarta: Erlangga, 2007.

Raguindin, Princess Zarla J., Ruby Leah S. Lising, dan Zhanina U. Custodio. "Strategies for Parental Involvement during Emergency Remote Teaching Scale: Its Psychometric Properties." European Journal of Educational Research 10, no. 1 (2021): 427-39.

Sallis, Edward. Total quality management in education. Yogyakarta: IRCiSoD, 2012.

Sanderson, Donna R. "Working Together to Strengthen the School Community: the Restructuring of a University-School Partnership." School Community Journal 26, no. 1 (2016): 183-98.

Sirotnik, Kenneth A., dan John I. Goodlad. School-University Partnerships in Action: Concepts, Cases,. ERIC, 1988. 
Snyder, Hannah. "Literature Review as a Research Methodology: an Overview and Guidelines.” Journal of Business Research 104 (2019): 333-39.

Tampubolon, Daulat Purnama. Perguruan Tinggi Bermutu: Paradigma Baru Manajemen Pendidikan Tinggi Menghadapi Tantangan Abad Ke-21. Gramedia Pustaka Utama, 2001.

Torraco, Richard J. "Writing Integrative Literature Reviews: Guidelines and Examples." Human Resource Development Review 4, no. 3 (2005): 356-67.

" "Writing Integrative Literature Reviews: Using the Past and Present to Explore the Future." Human Resource Development Review 15, no. 4 (2016): 404-28.

Wang, Ming-Te, dan Salam Sheikh-Khalil. "Does Parental Involvement Matter for Student Achievement and Mental Health in High School?" Child Development 85, no. 2 (2014): 610-25.

Whittemore, Robin, dan Kathleen Knafl. "The Integrative Review: Updated Methodology." Journal of Advanced Nursing 52, no. 5 (2005): 546-53.

Zeithaml, V. A., dan M. J. Bitner. Services Marketing: Integrating Customer Focus Across the Firm. Boston: Irwin/McGraw-Hill, 2000. 